\title{
Malos libros en la España del XVI: la fábula milesia de Vives a Venegas
}

\author{
Donatella Gagliardi \\ Università della Calabria \\ Studia Aurea 3 (2008) \\ Fecha de recepción: 29/05/2008, Fecha de publicación: 20/05/2008 \\ <URL: http://www.studiaaurea.com/articulo.php?id=86 >
}

La cruzada del maestro toledano Alejo Venegas contra la literatura milesia se inspiró en las obras e ideas de Juan Luis Vives. En el periodo de mayor auge de los libros de caballerías, ambos censuraron a los autores y lectores de estas ficciones engañosas que, a su entender, no eran sino una forma extremadamente dañina de poesía corrompida. En la interpretación más severa de Venegas, la mala secta de Amadises y Esplandianes es asimilada a las mendaces escrituras sagradas de musulmanes y judíos, que acaban siendo encasilladas bajo el mismo marbete de fábula milesia.

PALABRAS CLAVE EN ESPAÑOL: fábula milesia, libros de caballerías, siglo XVI, Vives, Venegas PALABRAS CLAVE EN INGLÉS: Milesian Fable, Romances of Chivalry, 16th Century, Vives, Venegas

Alejo Venegas de Busto (Camarena 1498 ca.- Toledo 1562) ${ }^{1}$ no es sólo el autor de una praeparatio ad mortem de inspiración erasmiana, titulada Agonía del tránsito de la muerte, que hizo mella en la historia de la teología ascética y pastoral de España, ${ }^{2}$ sino que como maestro de gramática, y censor y visitador de libros, ${ }^{3}$ glosó ediciones escolares, escribió tratados, ${ }^{4}$ opúsculos, aprobaciones por encargo de la Inquisición, y muchos prefacios a textos de contenido filosófico o religioso, cuya difusión quería promocionar e impulsar.

En toda su producción abundan las reflexiones sobre la ética de la lectura, con especial atención a los nefastos efectos de ciertas obras de entretenimiento -como las ficciones caballerescas-, de las que fue acérrimo enemigo. Es mi propósito reconstruir aquí motivos y antecedentes de la cruzada que Venegas llevó a cabo contra la literatura "milesia", esbozando su catálogo de libri vitandi. ${ }^{5}$

\footnotetext{
${ }^{1}$ La más exhaustiva biografía intelectual de Venegas sigue siendo la que esbozó Adeva (1987).

${ }^{2}$ Para un rápido recorrido por las varias etapas de transformación de las artes moriendi desde el siglo XV hasta la época barroca, véase Zuili en su introducción a Venegas (2001: XXIX-XXXIX).

${ }^{3}$ Eisenberg (1980) analiza esta faceta de su poliédrica actividad.

${ }^{4}$ Se han perdido desgraciadamente el "tractado de poesía que, si Dios quiere, saldrá tras este guión", anunciado en el De Orthographía, cf. Venegas (1531: eiij); y el De liberis educandis -cuya publicación parecía inminente a finales de 1548- que iba a ser dedicado a Juan de Vergara. Para una lista completa de las obras de Venegas que no llegaron a ver la luz pública, cf. Adeva (1987: 161-163).

${ }^{5}$ Presenté una versión previa de este trabajo en el XVI Congreso de la AIH (París 2007).
} 


\section{De las fábulas milesias.}

Desde Clemencín en adelante, todos los cervantistas han coincidido en atribuir a Venegas la primera definición de los distintos tipos de fábula (mitológica, apológica, milesia) que retomaría luego Alonso López Pinciano en la Philosophía antigua poética ${ }^{6}$ y, probablemente a través de él, Cervantes en el Quijote $(I, 47){ }^{7}$ En un principio se reconoció la fuente de ambos en el prefacio de Venegas -sobre el que volveré más adelante- a la traducción castellana del Momo realizada por Agustín de Almazán (1553), pero, en un estudio de 1983, Daniel Eisenberg hiló más fino, retrotrayendo la mención más antigua de dicha definición a 1541, año en que fue publicada la Theológica descripción de los misterios sagrados.

Esta obra póstuma de Alvar Gómez de Ciudad Real se imprime en Toledo, con un prólogo y un epílogo al pío lector redactados por Venegas, quien pronuncia, en la pieza final, una apasionada defensa de la verdadera poesía, ensalzada, en su opinión, por textos como el de Gómez, ${ }^{8}$ y que, sin embargo, con el paso del tiempo, se ha visto corrompida por las fábulas vanas. El calificativo no es baladí, dado que fábula es palabra sin connotación alguna, al igual que habla:

Primeramente este nombre fábula es lo mismo que habla, que así puede ser mala o buena como la habla. Tres maneras hay de fábulas. Una fábula es mitológica, que quiere decir habla que por cuento de admiración cuenta los secretos de naturaleza o historias notables, como lo declara Diodoro Sículo en su Biblioteca y Marco Tullio en los libros De natura Deorum. Otra fábula se dice apológica, que es un dibujo y figura de ejemplos que con admiración descubre las cosas buenas y malas que pasan entre los hombres. En esta escribió Esopo y en la primera todos los otros poetas. Hay otra fábula que se dice milesia, que es la que en romance se dice conseja. Dícese milesia de la

\footnotetext{
6 "Hay tres maneras de fábulas unas, que todas son fición pura, de manera que fundamento y fábrica todo es imaginación, tales son las Milesias y libros de cauallerías; otras ay que sobre una mentira y fición fundan una verdad, como las de Esopo, dichas apologéticas, las quales, debaxo de una hablilla, muestran un consejo muy fino y verdadero; otras ay que sobre una verdad fabrican mil ficiones, tales son las trágicas y épicas, las quales siempre, o casi siempre, se fundan en alguna historia, mas de forma que la historia es poca en respecto y comparación de la fábula; y assí de la mayor parte toma la denominación la obra que de la una u otra se haze"; cf. López Pinciano (1973: II, 12-13), edición que reproduzco con mínimos retoques gráficos. Sobre las vacilantes catalogaciones del género caballeresco en el Siglo de Oro, véase Gagliardi (en prensa).

${ }^{7}$ En palabras del canónigo, "según a mí me parece, este género de escritura y composición cae debajo de aquel de las fábulas que Ilaman milesias, que son cuentos disparatados, que atienden solamente a deleitar, y no a enseñar, al contrario de lo que hacen las fábulas apólogas, que deleitan y enseñan juntamente. $Y$ puesto que el principal intento de semejantes libros sea el deleitar, no sé yo cómo pueden conseguirle, yendo llenos de tantos y tan desaforados disparates [...]"; Quijote (1998: I, 547).

${ }^{8}$ En la Exposición del Momo, Venegas volverá sobre la relación entre religión y poesía, definiendo ésta última como la única ciencia humana que "nunca se amotina contra la magestad de su señora, la sacra Theología"; cf. Venegas (1553: s.f.).
} 
ciudad de Mileto en Ionia, adonde por la mucha ociosidad de la tierra se inventaron las consejas [...]. La obra presente va compuesta en el primero y segundo género en que la verdadera poesía consiste. ${ }^{9}$

Por otro lado, cuantos han querido documentar la historia de esta clasificación de las fábulas, no han dejado de citar al Vives del De ratione dicendi (1532), ${ }^{10}$ quien efectivamente, en un capítulo del libro tercero (que trata de cada una de las partes de la oratoria didáctica) distingue tres tipos de narraciones, según se propongan como fin explicar algo, persuadir o pasar el rato. Las milesias son las más deleznables por carecer de verdad, verosimilitud y utilidad, y ser, al cabo,

una pura pérdida de tiempo, como en los convites y tertulias de hombres y mujeres, cual lo es toda la literatura erótica. Fue Luciano el primero que a las conversaciones amatorias las llamó milesias, y Marciano Capella infligió este nombre a determinadas ficciones poéticas. Por dar un nombre preciso de autor de escritos milesios, daré el de Arístides, que escribió algunos libros de ese jaez, y Apuleyo un Asno famoso tomado de Luciano y luego enjaezado por él. Apuleyo, ya en el propio comienzo de la obra, dice claramente que tiene ese carácter. Dice: Ahora te voy a deleitar con esta novela milesia. Fábulas de éstas son las patrañas que cuentan las viejas a los niños para que no lloren o no molesten. ¿Qué utilidad reportaría dar fórmulas para un género idiota? Más idiota sería yo si tal hiciera. Muy de otro linaje son las ficciones poéticas, de las cuales hablaremos como cumple. ${ }^{11}$

Los dos ejemplos de autores "milesios" aducidos por Vives pertenecen al mundo clásico: Arístides, fundador del género, y el Apuleyo de los Metamorphoseon libri XI, estando su proyección hacia la contemporaneidad desprovista de cualquier valor literario, puesto que como a fábulas milesias ya no cabe considerar más que a los cuentos para niños. ${ }^{12}$ Un planteamiento, éste, que parece remitir al de Macrobio, según la acertada observación de Baranda. ${ }^{13}$

\footnotetext{
${ }^{9}$ Venegas (1541: s.f.).

${ }^{10}$ Véase por ejemplo Marcel Bataillon (1966²: 616-617, n. 20).

${ }^{11}$ Vives (1947-1948, II: 790).

12 Nótese que ya Erasmo de Rotterdam en la Declamatio de pueris instituendis (1529) había hablado en términos parecidos de los "ridenda delirantium anicularum fabulamenta", despreciables cuanto las canciones inútiles y vulgares y las fruslerías que aprenden y repiten las mujerzuelas, a las que cabía preferir, en la educación de los niños, "aut lepidam ex poetis fabellam, aut festivam sententiam, aut insignem historiolam, aut eruditum apologum [...]. Quantus autem esset ad eruditionem factus gradus, si pro his siculis, ut aiunt, gerris vanioribus, nec frivolis tantum, sed noxiis quoque, ea quae modo commemoravimus statim imbibissemus?". He preferido reproducir el original latino ya que Riber, en su traducción castellana (Erasmo 1956: 955), malinterpreta esta última frase. Para las fuentes del Adagium "Siculae nugae, gerrae", véase la nota de Margolin a Erasmo (1966: 576, n. 751).

13 "Macrobio ( $I, 6-12$ ) ofrece un doble sistema: unas fábulas han sido inventadas para procurar placer a los oyentes, otras para exhortarles a una vida honesta. Entre las primeras cita a los autores de comedias, Menandro, Petronio y Apuleyo: 'todo este género de fabulae, que sólo promete deleite para los oídos, la
} 
Años atrás, el humanista valenciano había dedicado un capítulo entero de su Institutio foeminae chistianae a la reflexión sobre los peligros de la lectura, ${ }^{14}$ Ilegando a establecer un verdadero canon de la buena y mala literatura, que se reflejaría luego en los dictámenes de muchos moralistas españoles del siglo XVI. Transcribo a continuación el pasaje en que se enumeran los libri vitandi, tal como fue impreso en la princeps que vio la luz en Amberes en 1524 y en la reedición basileense de 1538: ${ }^{15}$

\begin{tabular}{|c|c|}
\hline Institutio 1524 & Institutio 1538 \\
\hline $\begin{array}{l}\text { Hoc ergo curare leges congruit. Tum et } \\
\text { de pestiferis libris, cuiusmodi sunt in } \\
\text { Hispania Amadisus, Florisandus, } \\
\text { Tirantus, Tristanus Lugdunensis: } \\
\text { Celestina lena, nequitiarum parens. In } \\
\text { Gallia Lancilotus a lacu, Paris et Vienna, } \\
\text { Ponthus et Sidonia, Petrus Provincialis } \\
\text { et Magalona, Melusina. In hac Belgica } \\
\text { Florius et Albus flos, Leonella et } \\
\text { Canamorus, Turias et Floreta, Piramus } \\
\text { et Thisbe. Sunt in vernaculas linguas } \\
\text { transfusi ex Latino quidam, velut } \\
\text { infacetissimae Facetiae Poggii, Aeneae } \\
\text { Silvii Euryalus et Lucretia. Quos omnes } \\
\text { libros conscripserunt homines otiosi, } \\
\text { male feriati, imperiti, vitiis ac spurcitiae } \\
\text { dediti, in queis miror quid delectet nisi } \\
\text { tam nobis flagitia blandirentur. [...] } \\
\text { Profecto ridenda est maritorum } \\
\text { dementia qui permittunt suis uxoribus } \\
\text { ut eiusmodi legendis libris astutius sint } \\
\text { sceleratae. [...] Feminae igitur hi omnes } \\
\text { libri non secus quam vipera vel scorpius } \\
\text { vitandi. }\end{array}$ & $\begin{array}{l}\text { Hoc ergo curare leges et magistratus } \\
\text { congruit. Tum et de pestiferis libris, } \\
\text { cuiusmodi sunt in Hispania Amadisus, } \\
\text { Splandianus, Florisandus, Tirantus, } \\
\text { Tristanus, quarum ineptiarum nullus } \\
\text { est finis. Quotidie prodeunt novae: } \\
\text { Celestina lena, nequitiarum parens; } \\
\text { Carcer amorum. In Gallia Lancilotus a } \\
\text { lacu, Paris et Vienna, Ponthus et Sidonia, } \\
\text { Petrus Provincialis et Magalona, Melusina, } \\
\text { domina inexorabilis. }{ }^{16} \text { In hac Belgica } \\
\text { Florius et Albus flos, Leonella et } \\
\text { Canamorus, Turias et Floreta, Piramus et } \\
\text { Thisbe. Sunt in vernaculas linguas } \\
\text { transfusi ex Latino quidam, velut } \\
\text { infacetissimae Facetiae Poggii, Euryalus et } \\
\text { Lucretia, centum fabulae Boccacii. Quos } \\
\text { omnes libros conscripserunt homines } \\
\text { otiosi, male feriati, imperiti, vitiis ac } \\
\text { spurcitiae dediti, in queis miror quid } \\
\text { delectet nisi tam nobis flagitia } \\
\text { blandirentur. [...] Profecto ridenda est } \\
\text { maritorum dementia qui permittunt suis } \\
\text { uxoribus ut eiusmodi legendis libris } \\
\text { astutius sint pravae. [...] Feminae igitur hi } \\
\text { omnes libri non secus quam vipera vel } \\
\text { scorpius aversandi sunt. }{ }^{17} \text { a }\end{array}$ \\
\hline
\end{tabular}

discusión filosófica lo excluye de su santuario y los relega a las cunas de las nodrizas'. Esta variedad corresponde a las que Vives denomina milesias"; cf. Baranda (2007: 15, n. 45).

${ }^{14}$ Me refiero al capítulo quinto, que lleva el título "Qui non legendi scriptores qui legendi".

${ }^{15}$ Señalo en negrita las lecturas que sólo aparecen en uno de los dos textos, y en cursiva las adiáforas.

${ }^{16}$ A diferencia de Menéndez y Pelayo y Lorenzo Riber, quienes consideraban "domina inexorabilis" una aposición de Melusina, Marcel Bataillon lo interpretó como un título más de la nómina de lecturas peligrosas, reconociendo en él una clara referencia a la Belle Dame sans merci. Cf. Bataillon (1966: 615, n. 16).

${ }^{17}$ Vives (1996-1998, I: 44-50). 
En la literatura española, los libros de caballerías monopolizan claramente la atención censoria -al igual que las historias caballerescas en el caso francés o belga-, compartiendo protagonismo sólo con la Tragicomedia de Rojas y, a partir de la segunda edición de la Institutio, con la Cárcel de amor de Diego de San Pedro. Es éste uno de los tres nuevos textos que en la reimpresión de Basilea engruesan las filas de las obras malditas, junto con Las Sergas de Esplandián, primera continuación del Amadís, y el Decameron de Boccaccio.

Ahora bien, el eco del anatema de Vives resuena en un pasaje del Tratado de ortographía de Alejo Venegas (1531):

Pocas disciplinas hay en que no haya libros dañosos, o a lo menos, superfluos. Porque empecemos de nuestra lengua castellana: no nos embiaría a decir desde Lovaina Ludovico Vives tanto mal de nuestros libros vulgares, si viera él que, en alguna manera, se podía soportar corrupción de costumbres, y por eso, allende de los Amadises y los Tirantes ${ }^{18}$ con toda su clase, con mucha razón difunde su satírica saña en la lena de Celestina, que en mi verdad no hay Marcial que tanto mal haga en latín, quanto esta flora patente desflora la juventud en romance. ${ }^{19}$

Sin embargo, es en otra página vivesiana donde se encuentra el eslabón que une el catálogo de malos libros de la Institutio con la teorización del De arte dicendi: me refiero al capítulo IV del De officio mariti (1529), que trata de la instrucción femenina, y más concretamente, en lo que concierne al fragmento que cito a continuación, de ciertas lecturas nocivas:

Voluptates titillant pleraque poetarum opera et Milesiae fabulae, ut Asinus Apuleii et fere Luciani omnia, quales crebrae sunt in linguis vernaculis scriptae: Tristani, Lanciloti, Ogerii, Amadisii, Arturi, et his similes. Qui libri omnes ab otiosis hominibus et chartarum abundantibus per ignorantiam meliorum sunt conscripti. Hi non feminis modo verumetiam viris officiunt, quemadmodum ea omnia quibus nutus iste noster ad peiora detruditur, ut quibus armatur astutia, accenditur habendi sitis, inflammatur ira aut cuiuscumque rei turpis atque illicita cupiditas. ${ }^{20}$

\footnotetext{
${ }^{18}$ Es éste un clásico ejemplo del que Sarmati (1996: 54-56) llama "topos dell'abbondanza" en su análisis de las censuras caballerescas. El uso del plural por el singular se explicaría con la intención "di squalificare gli esemplari negandone l'identità individuale".

${ }^{19}$ Venegas (1986: 66).

${ }^{20}$ Vives (2006: 122). La versión castellana de este fragmento propuesta por Carme Bernal es la siguiente: "La voluptuosidad impregna la mayor parte de las obras de los poetas; las fábulas milesias como el «Asno de oro» de Apuleyo; casi todas las de Luciano; las que en elevado número se han escrito en lenguas vernáculas, como Tristan, Lancelot, Ogeres, Amadises, Arturos y otras semejantes. Todos estos libros fueron escritos por hombres ociosos, con mucho papel a su alcance, ignorantes en temas de mayor altura.
} 
El valenciano ratifica aquí su propio índice de textos dañinos para la conducta moral, y por vez primera asemeja la literatura caballeresca a las fábulas milesias, lo cual creo que no se ha puesto de relieve hasta la fecha. Para ceñirnos a la producción española, los Amadises se sitúan para él en el mismo plano que el Asinus aureus, puesto que tanto el uno como los otros están fundados sobre ficciones engañosas, que despiertan pensamientos lascivos. Son obras que deberían estar terminantemente prohibidas, porque "ya es nuestra naturaleza suficientemente proclive al mal, como para necesitar estímulos ni que se aplique al fuego estopa o aceite".

Las advertencias de Vives no fueron desoídas por Venegas, quien aprovechó toda ocasión para abogar por una censura más severa de las fábulas milesias. Lo impulsaba el deseo de beneficiar al prójimo, y máxime a la gente vulgar, incapaz, en su opinión, de distinguir entre apariencia y verdad, ${ }^{21}$ y convencida de que

qualquier libro impresso tiene auctoridad para que le crean lo que dixere. De donde acontece que muchas vezes beve ponzoña por medicina, y haze sacomano de la mentira so color de verdad. Por donde es cierto que, si no pudiera dañar la lición de los malos libros, nunca la sancta madre iglesia pusiera su decreto en aprovar unos y reprovar otros, como claramente parece en la décima quinta y tricésima séptima distinctión del decreto. Por lo qual, si los libros que después se escrivieron, que por las vanidades que tratan los podremos dezir Milesios, fueran en el tiempo que se hizieron estos decretos y viniera a noticia de la iglesia el notable daño que de la lición destos resulta, de creer es que los vedara la iglesia como libros notablemente dañosos. Pues muchos de los libros que pronunció por inútiles y dañosos son mucho mejores, o por mejor dezir menos dañosos que estos vulgares Milesios que estragan las ánimas tiernas de los ignorantes y rudos lectores. ${ }^{22}$

A esta misión se aplica el maestro de Camarena en el prólogo que escribe en 1546 para la recopilación de obras que su discípulo predilecto, Francisco Cervantes de Salazar, glosó y vertió al castellano: ${ }^{23}$

Perjudican tales lecturas no sólo a las mujeres sino también a los hombres, al igual que aquellas que animan esta inclinación natural que tenemos a lo malo; las que dan armas a la astucia, las que encienden la sed de codicia, las que inflaman la ira o cualquier deseo de cosas ilícitas y vergonzosas"; cf. Vives (1994: 134).

${ }^{21}$ No todos los moralistas y religiosos de la época compartían la opinión de Venegas. Cabe destacar a este propósito el interesantísmo testimonio, citado y comentado por Prosperi (2003: 347), del comisario general del Santo Oficio romano, Michele Ghislieri, quien, en una carta de 1557 al Inquisidor de Génova afirmó que "col prohibire Orlando, Orlandino, Cento novelle et simili altri libri piú presto daressemo da ridere ch'altrimente, perché simili libri non si leggono come cose a qual si habbi da credere, ma come fabule, et come si leggono ancor molti libri de gentili come Luciano, Lucretio et altri simili".

${ }^{22}$ Venegas (1983: s.f.). Entresaco la cita del prólogo-dedicatoria a la Primera parte de las diferencias de libros que hay en el universo, dirigido al obispo Juan Bernal Díaz de Luco y redactado en noviembre de 1539. La princeps de la obra se publicó al año siguiente. 
[...] porque la presente oportunidad es raíz de mucho aprovechamiento, acordé dar una breve relación de las obras presentes, viendo que, con semejantes trabajos, salen ya poco a poco de entre las manos de los píos lectores los libros que, en el principio de su obra mayor, llama Apuleyo libros milesios, que son los libros de vanidades enervoladas, que, con mayor verdad, se dirían sermonarios de Sathanás que blasones de cavallerías; porque vemos que veda el padre a la hija que no le venga y le vaya la vieja con sus mensajes, y por otra parte es tan mal recatado que no le veda que, leyendo Amadises y Esplandianes con todos los de su vando, le esté predicando el diablo a sus solas, que allí aprende las celadas de las ponçoñas secretas, demás del hábito que haze en pensamientos de sensualidad, que assí la hazen saltar de su quietud, como el fuego a la pólvora. ${ }^{24}$

Algo más tarde, en el largo prefacio a la traducción de La moral y muy graciosa historia del Momo [...] trasladada en castellano por Augustín de Almazán (1553), Venegas arremete de nuevo contra la fábula milesia, contra ese "desvarío vano sin meollo de virtud ni ciencia, urdido para embobecer a los simples", según su propia definición. Lo que no deja de sorprender en este punto es que etiquete bajo el marbete de "fábula milesia" no sólo a las obras más en boga del género caballeresco, como cabía esperar, sino también a los libros sagrados de musulmanes y judíos.

\section{La verdad embadurnada.}

Con un "Ineptas autem et aniles fabulas devita" amonestó San Pablo a Timoteo (en la epístola I), y para Venegas las palabras del apóstol, interpretadas como "fábulas vanas y cuentos de viejas", son las mejores que puedan hallarse para calificar las escrituras más veneradas de otras religiones. Ya en el epílogo a la Theológica descripción de los misterios sagrados (1541) había juzgado el Alcorán comparable a las ponzoñosas ficciones caballerescas:

En esta fábula [milesia] escribió Apuleyo su Asno dorado y Mahoma escribió su Alcorán, y todos los Milesios escribieron sus caballerías amadísicas y esplandiánicas herboladas. De este género de fábulas amonesta el apóstol a Timoteo que huiga. ${ }^{25}$

Sin embargo, en el prefacio al Momo castellano su invectiva contra las falsas creencias religiosas se hace aún más violenta y circunstanciada:

\footnotetext{
${ }^{23}$ Venegas fue uno de los padrinos de Cervantes de Salazar que promocionaron dicha publicación, como revela él mismo en el mencionado prólogo.

${ }^{24}$ Venegas (1546: s.f.). Para una edición moderna de esta pieza liminar, cf. Zuili (1999).

${ }^{25}$ Venegas (1541: s.f.).
} 
Hay otra tercera diferencia de fábulas, que no están debajo de la poesía racional, sino de la corrupta: las cuales de la ciudad de Mileto, que es en Jonia, donde se inventaron, se llamaron milesias. De esta diferencia de fábulas vanas amonesta el apóstol a Timoteo que huiga en el capítulo IV de la primera epístola. En este tercero género de fábulas desvariadas están escritos el libro de la Cábala y el Talmud de los judíos, con que sofísticamente aun no pueden defender los desatinos de su incredulidad. En este género de fábulas milesias está escrito el Alcorán de Mahoma, a quien los moros llaman Muhamedes, que es una secta cuarteada, cuyo principal cuarto es la vida porcuna que dicen epicúrea. El segundo es tejido de ceremonias judaicas vacías del significado que solían tener antes del advenimiento de Cristo. El tercero cuarto es de las herejías arriana y nestorea. El cuarto es la letra del evangelio, torcida y mal entendida, conforme a su desvariado propósito. También son fábulas milesias de este jaez la Çuna ${ }^{26}$ y la Xara que urdieron los moros en su iglesia de malignantes. En esta diferencia de fábulas escribió Apuleyo su Asno dorado y en nuestros tiempos con detrimiento de las doncellas recogidas se escriben los libros desaforados de caballerías, que no sirven sino de ser unos sermonarios del diablo, con que en los rincones caza los ánimos tiernos de las doncellas. ${ }^{27}$

Es éste que acabamos de ver el más completo catálogo de malos libros de cuantos Venegas apuntó en las muchas piezas liminares que llevan su firma. ${ }^{28}$ Cabe preguntarse qué tienen en común las vanidades caballerescas con la recopilación de dichos y enseñanzas del profeta Mahoma (Suna), o con la doctrina hebrea místicoesotérica (Cábala). Quizá la clave de esta peculiar yuxtaposición se encuentre una vez más en las obras (e ideas) de Vives. In primis en la Introductio ad sapientiam (1524), que fue uno de los textos traducidos y glosados por Cervantes de Salazar. En ella el valenciano extremaba las recomendaciones a fin de evitar "toda arte introducida por el demonio, con quien como enemigo de Dios no hemos de querer ninguna suerte de tratos". Y proseguía observando que

\section{CXXXVII}

$\mathrm{Ni}$ aun es bueno conocer los postulados de los filósofos o de los herejes contrarios a nuestra religión; porque el demonio, espíritu muy sutil, no meta arteramente en nuestras almas algún escrúpulo que nos ocasione viva molestia y acaso nos empuje a la perdición.

\section{CXXXVIII}

\footnotetext{
${ }^{26}$ En el texto se lee Cuma, pero en el errata corrige antepuesto a la "Tabla de la presente obra" se señala la lección exacta.

${ }^{27}$ Venegas (1553: s.f.).

${ }^{28}$ Para un repertorio completo, cf. Adeva (1987: 160-161).
} 
Asimismo, ni siquiera se han de tocar los autores sucios, porque no se nos pegue el contagio de ninguna suciedad. Corrompen las buenas costumbres los malos tratos. ${ }^{29}$

Así no es ninguna casualidad que en la edición de Cervantes de Salazar inmediatamente después se lea una de sus adiciones más conocidas: "En esto se avía más de cargar la mano y es en lo que más nos descuydamos, porque tras el sabroso hablar de los libros de cavallerías, bevemos mill vicios, como sabrosa ponçoña, porque de allí viene el aborrecer los libros sanctos y contemplativos, y el dessear verse en actos feos, quales son los que aquellos libros tratan $[\ldots]$ ". Como era de prever, las reflexiones del discípulo siguen la estela de las del maestro: Amadises y Esplandianes al igual que los textos heterodoxos o de otras religiones comparten la misma naturaleza de satánicas y venenosas mentiras que llevan a la perdición. El "sermo milesius" que Filippo Beroaldo, a principios del XVI, en su comentario al Asinus Aureus, definía como "fabulosus, lepidus, iocosus aut delicatus", ${ }^{30}$ cincuenta años más tarde ha pasado a ser sinónimo de discurso vano, licencioso, mentiroso y hasta herético, ${ }^{31}$ es decir la variante más peligrosa de los colloquia prava, en la interpretación erasmiana:

Iam vero quod de colloquio dictum est, idem oportet et de studiis accipere. Qui vitam omnem in ethnicis conterunt literis, gentiles evadunt. Qui praeter obscoenos autores nil evolvunt, moribus obscoenis reddantur oportet. Etenim lectio colloquium quoddam esse videtur. $^{32}$

Puesto que la palabra encierra una fuerza arcana que puede ser salvífica o destructiva, según su esencia y finalidad, inoculando en el ánimo de quien la escucha "praesentaneum venenum, si pestilens fuerit, remedium efficax, si salutaris", ${ }^{33}$ para el maestro de Camarena las ficciones caballerescas, al ser vanidades "enervoladas", ${ }^{34}$ caben indiscutiblemente entre los sermonarios diabólicos, ${ }^{35} 0$, como diría el cura

\footnotetext{
${ }^{29}$ Vives (1947-1948, I: 1217).

${ }^{30}$ Cito de la edición de 1500, publicada en Bolonia, apud Benedictum Hectoris.

${ }^{31}$ Reúno aquí las distintas tipologías de "libros del demonio" descritas por Fray Luis de Alarcón. Para un análisis de esta clasificación, cf. Gagliardi (2004: 143-145).

${ }^{32}$ Erasmo, Adagia, I 10, 74.

${ }^{33}$ Ibidem.

${ }^{34}$ Cf. el prólogo ya citado en la p. 7 del presente trabajo. En el epílogo a la Theológica descripción de los misterios sagrados encontramos la variante "hervoladas". 'Enherbolado' es "part. pass. del verbo enherbolar. Envenenado, conficionado con hierbas venenosas. Lat. Veneno infectus"; cf. Diccionario de Autoridades s.v. Enherbolado. Como adjetivo está documentado, entre otros textos, en el Libro de Buen Amor (I, 224) y en las Églogas de Garcilaso (II, 726).

${ }^{35}$ En 1598 Juan Sánchez Valdés de la Plata, en el prólogo a la Corónica y historia general del hombre, retomará al pie de la letra los argumentos de Venegas, censurando a cuantos leen "libros de vanidades
} 
cervantino, entre las "malas sectas". ${ }^{36}$ Una idea, ésta, que, a finales del XVI, Antonio Possevino sostendría hasta sus extremas implicaciones, afirmando en una famosa página de la Bibliotheca selecta que fue el demonio quien inspiró la traducción al francés del Amadís para propiciar la difusión de las ideas luteranas:

[...] quo non intrarunt Lancelotus a Lacu, Perseforestus, Tristanus, Giro Cortesius, Amadisius, Primaleo, Boccaciique Decamero, et Ariosti poema? Ne hic enumerem aliorum ignobiliorum poetarum carmina male texta et care vendita. Et plerisque igitur istis omnibus, ut suavius venena influerent, dedit de spiritu suo Diabolus, eloquentia et inventione fabularum ditans ingenia, quae tam miserae supellectilis voluere esse officinae. In uno Amadisio ista intueamur. Venerat hic liber aliena lingua in Gallias: Luthero autem Satanas iam utebatur tamquam mancipio in Germania, quae pene omnis aut ceciderat, aut nutabat ad casum; cumque in solidissimae fidei regnum vellet invadere, Amadisium curavit in Gallicam linguam elegantissime verti. Haec prima fuit illecebra et tamquam sibilus, quo inescavit nobilium aulicorum ingenia. [...]. Nam sic ablegata sunt studia sacrarum rerum, divinaeque historiae oblivioni sunt traditae, atque harum loco Pantagrueles et ramenta quaeque Tartari successerunt, praelia Domini ignorata, invocatio omnipotentis Dei omissa, blasphemiae receptae, labes et libido tamquam torrens invecta; proque veris militaribus studiis, hic male sanus Satanae novitiatus professionem pessimam militiae praecessit. ${ }^{37}$

Volviendo a los libros sagrados de judíos y musulmanes, algún que otro pasaje del De veritate fidei (1543), tratado póstumo del Vives, parecería corroborar la asimilación de dichos textos a las patrañas milesias. Véase, por ejemplo, en una de las réplicas puestas en boca del cristiano en su diálogo con el judío, la terminología utilizada para connotar ciertas interpretaciones de los rabinos que mistifican maliciosamente el sentido primordial del verbo divino:

Transeo nugas plusquam pueriles [...] nam tibi multo sunt quam mihi notiora. Tum historias rerum, et rerum narrationes non solum apertissime mendaces, sed ineptissime ac stultissime narratas [...], et ad haec adeo ridicula non veremini detorquere maiestatem sanctarum literarum. Congeritis loca ex Iob, Esaia, Psalmis, et quae sancti

enerboladas, que con mayor verdad se dirían sermonarios de Satanás, y blasones de cavallerías de Amadises y Esplandianes con todos los de su vando, de los quales no sacan otro provecho, ni otra dotrina, sino hazer hábito en sus pensamientos de mentiras y vanidades, que es lo que mucho el diablo siempre codicia, para que con estas ponzoñas secretas y sabrosas, las aparte del camino verdadero de Iesu Christo nuestro Redentor"; citado por Sarmati (1996: 167).

${ }^{36}$ Véase, en el celebérrimo episodio del escrutinio al que el barbero y el cura someten la biblioteca de Don Quijote, el juicio formulado sobre el Amadís: "este libro fue el primero de caballerías que se imprimió en España, y todos los demás han tomado principio y origen deste; y así, me parece que, como a dogmatizador de una secta tan mala, le debemos sin escusa condenar al fuego". Cf. Quijote (1998: I, 77). La cursiva es mía.

${ }^{37}$ Possevino (1593: 113-114). El capítulo del que procede la cita no en vano se titula: "De Amadisio et aliis eiusmodi libris, quos variis linguis hoc novissimo saeculo editos, nobiles potissimum versarunt, magno pietatis damno, ad Magiam vero, et ad sortilegia, denique et ad haeresim ostio per eos patefacto". 
homines per metaphoram ut mos erat tum loquendi, ad spiritalem referebant intelligentiam, vos in coenum carnalitatis impie atque impudenter detruditis. ${ }^{38}$

\section{Y más adelante:}

Exolevit paulatim inter vos lectio sanctarum literarum, illas tanquam rem vetustate exanguem et languidam reliquistis, amplexi enarrationes commenta et somnia vestrorum rabinorum, ex quibus conflatum est Thalmud, quod maioris esse apud vos authoritatis coepit, quam ipsa Dei oracula. ${ }^{39}$

Si el Talmud para Vives no era más que la suma de fábulas y delirios de los intérpretes judíos, un juicio no menos contundente merecía para él el libro por antonomasia de la ley de Mahoma, que, en su opinión, añadió mentiras a mentiras: "nec minus secure infinita mendacia in Alcorano confingit partim ex Thalmut Iudaeorum, quae tamen ipse magis corrupit [...]. Ita plenus est fabularum similium Thalmudicis". ${ }^{40}$ Ataques feroces, como puede comprobarse, de los que se haría eco Bibliander en su Apologia pro editione Alcorani, censurando la doctrina musulmana en cuanto "summa delle eresie antiche, nate dal messaggio cristiano come sua deformazione, come una religione al tempo troppo razionale e puerile, fabulosa": ${ }^{41}$

Qua ratione alcoranum inter doctrinas haereticas rectissime constituemus: praesertim cum eius perversa dogmata reperiantur ab aliis ante ipsum, haereticis iactata esse [...]. In alcorano scatent absurda mendacia [...] sine ordine res congeruntur, omniaque spargunt confuse ac perturbate, ut quaedam labyrintho inexplicabiliora sint, etiam confessione illorum qui exercitati sunt in doctrina Machumetis [...] doctrina Machumetis scoria, et inanes paleae, et densissimae tenebrae iudicari debet. ${ }^{42}$

Ya que en el mundo cristiano el Talmud y el Alcorán eran tildados de "fábulas", que habían adulterado, falseado, y hasta depravado el Verbum Dei, no debe sorprender que Venegas reconociera en ellos el mismo estatuto de fingimiento mendaz e inmoral que en las milesias, por ser perversas manipulaciones de la verdad, que no podían justificarse bajo ningún concepto. En la Veritas Fucata de 1523 Vives no había dejado margen de duda acerca de los límites del recurso a la ficción. ${ }^{43}$ Léanse, como botón de muestra, dos de las diez condiciones impuestas por la Verdad a los Falsiani:

\footnotetext{
${ }^{38}$ Vives (1543: 233).

${ }^{39}$ Ibidem: 247.

${ }^{40}$ Ibidem: 348; 381-382.

${ }^{41}$ Felici (2007: 11). Theodor Buchmann, conocido como Bibliander, filólogo, teólogo y lingüista de renombre, promovió en 1543 la publicación en latín del Alcorán en una célebre edición basileense, que reunió también los principales textos sobre la civilización islámica y la literatura apologética antialcoránica. El segundo de los tres tomos de la obra incluía, como era de esperar, excerpta del De veritate fidei de Vives.

${ }^{42}$ Citado por Felici (2007: 11).
} 
Octava condición. Si en la compostura y afeite de la Verdad no existe verosimilitud ni congruencia ni decoro, la obra disonante, absurda, ridícula, que de ahí naciere, debe ser pateada, debe ser silbada, debe ser rechazada inexorablemente.

Novena condición. Si alguno, para su propio esparcimiento, tuviere el propósito de ir a la zaga de lo Falso, sin tener cuenta con la moralidad ni la utilidad práctica, porque no le falte cortejo a ese príncipe, se le toleraría la compañía siempre que se distinga por alguna insignia visible; déseles ciudadanía en alguna villa milesia, amena y regalada; vayan con ellos risas y donaires; vayan con ellos las dos esposas de Vulcano y vivan con Luciano, Apuleyo y Clodio Albino. ${ }^{44}$

Venegas, consciente de la "creciente demanda de ficción que revela[ba] el progresivo gusto por la literatura como entretenimiento" ${ }^{45}$ por parte de los lectores españoles, no desdeñó asignar también a la fábula apológica -como a los textos sagrados- la misión de contrarrestar la avanzada de los "milesios", lo que le impulsó a favorecer, por ejemplo, la publicación del Apólogo de la ociosidad y el trabajo y del Momo en versión castellana. ${ }^{46}$

Si Vives dio inicio a la cruzada en pro de una literatura verdadera y provechosa -una empresa que continuaría a lo largo de todo el siglo XVI-, fue Venegas quien acuñó la metáfora militar, al confesar en el prefacio al Momo, el inmenso placer espiritual que experimentaba viendo cómo "cada día salen escuadrones de buenos libros, en que se lee el antídoto contra la pestilencia encubierta debaxo de buen estilo en los libros milesios desaforados". A la guerra santa contra infieles, herejes y falsiani se sumaban también, gracias a ellos, ejércitos de papel y tinta.

\footnotetext{
${ }^{43}$ La Veritas fucata, cuya princeps se remonta a 1514, apareció también, con algunos cambios, en la edición de Opuscula varia de 1519. El texto que Vives publicó en 1523 con el título ampliado Veritas fucata, sive de licencia poetica, es fruto de una sustancial reescritura de la obra, que cobra forma de diálogo entre Vives y su amigo Juan de Vergara. Para una breve presentación de las dos versiones, cf. Fantazzi en su introducción a Vives (1987: 61-63).

${ }^{44}$ Riber (I, 892).

45 Baranda (2007: 16).

${ }^{46}$ Sobre la interpretación de la obra de Alberti por parte de Venegas y Almazán, véase Vega (1998).
} 


\section{Bibliografía.}

Adeva Martín, Ildefonso, El maestro Alejo Venegas de Busto: su vida y sus obras, Toledo, Diputación Provincial, 1987.

Baranda, Consolación, "El apólogo y el estatuto de la ficción en el Renacimiento", Studia Aurea n. 1 (2007); http://www.studiaaurea.com/articulo.php?id=45

Bataillon, Marcel, Erasmo y España: estudios sobre la historia espiritual del siglo XVI, México-Buenos Aires, Fondo de Cultura Económica, 1966².

Cervantes, Miguel de, Don Quijote de la Mancha, edición del Instituto Cervantes dirigida por Francisco Rico con la colaboración de Joaquín Forradellas, estudio preliminar de Fernando Lázaro Carreter, Barcelona, Instituto Cervantes, Crítica, 1998.

Cervantes de Salazar, Francisco, Adiciones a la Introducción y camino para la sabiduría de Juan Luis Vives (1546) en Obras que Francisco Cervantes de Salazar ha hecho glosado y traduzido, Alcalá de Henares, Joan de Brócar, 1546.

Eisenberg, Daniel, "An Early Censor: Alejo Venegas", en Medieval, Renaissance and Folklore Studies in honor of John Esten Keller, Newark, Juan de la Cuesta, 1980, pp. 229-241. 
----- (1983), vid. Venegas (1983).

Erasmo de Rotterdam, Obras escogidas, traslación castellana directa, comentarios, notas y un ensayo biobibliográfico por Lorenzo Riber, Madrid, Aguilar, 1956.

-----, Declamatio de pueris statim et liberaliter instituendis, étude critique, traduction et commentaire par Jean-Claude Margolin, Genève, Droz (Travaux d'humanisme et Renaissance), 1966.

Fantazzi, Charles (1987), vid. Vives (1987).

Felici, Lucia, "L'Islam in Europa. L'edizione del Corano di Theodor Bibliander (1543)", Cromohs, 12 (2007), 1-13.

Gagliardi, Donatella, "Voluptuosa Musa: la censura de la lírica de amor en la España del siglo XVI" en Idea de la lírica en el Renacimiento (entre Italia y España), al cuidado de María José Vega y Cesc Esteve, Pontevedra, Mirabel Editorial, 2004, pp. 143-178.

-----, "Entre fábula, épica e historia. Definiciones del género caballeresco en la España del XVI", en prensa.

López Pinciano, Alonso, Philosophía antigua poética, edición de Alfredo Carballo Picazo, Madrid, CSIC, 1973, 3 vols.

Margolin, Jean-Claude (1966), vid. Erasmo (1966).

Possevino, Antonio, Bibliotheca selecta, Romae, Ex Typographia Apostolica Vaticana, 1593.

Prosperi, Adriano, "Censurare le favole" en L'inquisizione romana. Letture e ricerche, Roma, Edizioni di Storia e Letteratura, 2003, pp. 345-384. 
Riber, Lorenzo (1947-1948) vid. Vives (1947-1948).

----- (1956) vid. Erasmo de Rotterdam (1956).

Sarmati, Elisabetta, Le critiche ai libri di cavalleria nel Cinquecento spagnolo (con uno sguardo sul Seicento). Un'analisi testuale, Pisa, Giardini Editori (Collana di testi e studi ispanici), 1996.

Vega, María José, "Traducción y reescritura de L.B. Alberti: el Momo castellano de Agustín de Almazán", Esperienze letterarie (1998), anno XXIII, n. 2, pp. 13-41.

Venegas, Alejo, Tractado de orthographía y accentos en las tres lenguas principales, Toledo, en casa de Lázaro Salvago Ginovés (1531); estudio de Lidio Nieto y edición facsímil, Madrid, Arco Libros, 1986.

-----, "Prólogo" y "epílogo" a Theológica descripción de los misterios sagrados de Alvar Gómez de Ciudad Real, Toledo, Juan de Ayala, 1541.

-----, "Prólogo" a Luis Mejía, Apólogo de la ociosidad y el trabajo, en Obras que Francisco Cervantes de Salazar ha hecho glosado y traduzido, Alcalá, Joan de Brócar, 1546.

-----, "Prólogo" a Leon Battista Alberti, La moral y muy graciosa historia del Momo [...] trasladada en castellano por Augustín de Almazán, Alcalá de Henares, Juan de Mey, 1553.

-----, Primera parte de las diferencias de libros q[ue] ay en el universo, prólogo de Daniel Eisenberg, Barcelona, Puvill Libros, 1983.

-----, Agonía del tránsito de la muerte, édition critique avec introduction et notes par Marc Zuili, Paris, L'Harmattan, 2001.

Vives, Juan Luis, De veritate fidei christianae libri quinque, Basileae, Ex officina Io. Oporini, 1543. 
-----, Obras completas. Primera traslación castellana íntegra y directa, comentarios, notas y un ensayo biobibliográfico por Lorenzo Riber, Madrid, Aguilar, 1947-1948, 2 tomos.

-----, Early writings. De initiis sectis et laudibus philosophiae, Veritas fucata, Anima senis, Pompeius fugiens, introduction, critical edition, translation and notes, edited by C. Matheeussen, C. Fantazzi, E. George, Leiden-New York-København-Köln, Brill, 1987.

-----, Los deberes del marido, traducción, introducción y notas por Carme Bernal, Valencia, Ayuntamiento de Valencia, 1994.

-----, De institutione feminae christianae, edited by C. Fantazzi and C. Matheeussen, translated by C. Fantazzi, Leiden-New York-Köln, Brill, 1996-1998, 2 vols.

-----, De officio mariti, introduction, critical edition, translation and notes, edited by C. Fantazzi, Leiden-Boston, Brill, 2006.

Zuili, Marc, "Alejo Venegas, auteur de prologues: édition annotée de son Prólogo al lector dans les Obras que a hecho, glosado y traduzido Francisco Cervantes de Salazar (1546)" en Hommage à Jean Bélorgey. Paroles et cultures, s.I., Université de Cergy-Pontoise, 1999, pp. 17-35. 